9IKC Abstracts,

Vol. 1, 9IKC-A-00345, 2008

9th International Kimberlite Conference

(C) Author(s) 2008

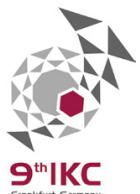

\title{
PGE fractionation in mantle sulfides: fingerprints of metasomatic processes
}

K.-L. Wang (1,2), S. Y. O'Reilly (2), W. L. Griffin (2), N. J. Pearson (2) and M. Zhang (2)

(1) Institute of Earth Sciences, Academia Sinica, Taipei, Taiwan, R.O.C., (2) GEMOC Key

Centre, Dept. of Earth and Planetary Sciences, Macquarie University, Sydney, Australia

(klwang@gate.sinica.edu.tw / Fax: +886 2 27839871)

Analyses of mantle sulfides have demonstrated the high solubility of the Platinum Group Elements (PGEs) in base metal sulphides (BMS) and show that the PGE budget of mantle rocks is fully controlled by the BMS. If they are not enclosed inside refractory silicate or oxide phases, sulfides are likely to be mobile in the lithospheric mantle and their absolute and relative abundances of PGEs can be altered by metasomatic processes. Abundant primary sulfides occur both as inclusions in silicates and as interstitial grains in spinel lherzolite and pyroxenite xenoliths hosted by Miocene intraplate basalts from the Penghu Islands, Taiwan. Modally metasomatised xenoliths with amphibole can have sulfide abundances up to $1 \mathrm{vol} . \%$, whereas cryptically metasomatised samples, with re-enriched trace-element patterns in clinopyroxenes, have $0.1 \sim 0.3$ vol.\% sulfides. These sulfides are mixtures of Fe-rich and Ni-rich monosulfide solid solutions (MSS), pentlandite, millerite and chalcopyrite, exsolved from high- temperature $\left(>900^{\circ} \mathrm{C}\right)$ MSS bulk compositions.

Most Penghu sulfides are interstitial to the silicate phases, suggesting a metasomatic origin. Two distinct groups of sulfides, from the Kueipi (KP) village and Tungchiyu (TCY) islet separately, are distinguished by their reconstructed major-element compositions. Sulfides from both groups have lower Os and Ir abundances than typical residual MSS and have PGE patterns within the range of typical sulfide melts; the KP sulfides have more irregular PGE patterns than the TCY sulfides, with high Ru-Rh and low Pt-Pd. The so-called P-PGEs $(\mathrm{Pd}+\mathrm{Pt})$ in the two groups of sulfides are fractionated relative to the I-PGEs ( $\mathrm{Ir}+\mathrm{Os}$ ). Because the P-PGEs and Re are relatively in- 
compatible elements during melting processes, these patterns suggest that both groups of sulfides have been metasomatised by silicate melts. Os behave coherently with Ir in the TCY sulfides, but in the KP sulfides, Ir and Os are only weakly correlated. This I-PGE fractionation is not likely to be caused by silicate metasomatism, considering the similar partition coefficients of the I-PGEs, so another metasomatic agent is suggested. Aqueous fluids/low density supercritical fluids may fractionate Os from Ir (Lee, 2002; Lorand et al., 2004), and it is likely that such fluids have affected some of the KP sulfides to fractionate their I-PGEs.

Our previously published Os isotope data (Wang et al., 2003) show these KP sulfides have undergone one unique type of Os disturbance: the addition of radiogenic Os, with little or no addition of Re. The introduction of highly radiogenic Os may be caused by an oxidizing hydrous fluid carrying Os, but not Re. In these KP sulfides, metal/sulfur ratios are negatively correlated with ${ }^{187} \mathrm{Os} /{ }^{188} \mathrm{Os}$, showing that sulfides equilibrated under oxidising conditions have higher ${ }^{187} \mathrm{Os} /{ }^{188} \mathrm{Os}$. It may indicate crystallographic changes of sulfides from MSS to pentlandites by removal of sulfur, to cause efficient Os removal and Re addition in the new pentlandite phase, then the metasomatic agent with radiogenic Os and low Re could easily affect the new sulfide phases. The unique metasomatic agent causing fractionation of I-PGEs coupled with enrichment in (radiogenic) Os may reflect specific processes that remain to be identified. 